\title{
TRIPLE-NEGATIVE BREAST CANCER
}

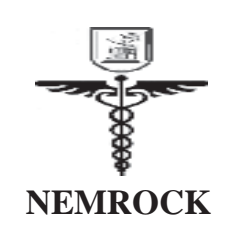

Salah El-Mesidy and Amr El-Kashif

\author{
Department of Clinical Oncology, Faculty of Medicine, Cairo University.
}

\begin{abstract}
Breast cancers are represented by a heterogeneous group of tumors, characterized by a wide spectrum of clinical, pathologic and molecular features ${ }^{1-3}$. This wide spectrum of factors accounts for variations in response to therapy and outcomes among women diagnosed with breast cancer $^{4-6}$. Steroid hormone receptors (HR) such as estrogen receptor (ER) and progesterone receptor (PgR) in concert with the oncogene ErbB-2/human epidermal growth factor receptor 2 (HER-2) are critical determinants of these BC subtypes. While HR are thought to mirror a good prognosis, expression of HER-2 has long been understood as an unfavorable prognostic feature ${ }^{7,8}$.
\end{abstract}

Classification of breast cancers into basal type (triple negative), luminal and HER2/neu has been proposed as a classification scheme based on gene expression profiles. It has been demonstrated that this classification scheme has prognostic significance and implications with respect to response to therapy ${ }^{1,2}$.

Triple-negative breast cancer (TNBC) is defined by a lack of expression of both estrogen and progesterone receptor as well as HER-2. It is characterized by distinct molecular, histological and clinical features including a particularly unfavorable prognosis despite increased sensitivity to standard cytotoxic chemotherapy regimens ${ }^{9}$.Luminal subtypes make up the hormone receptor-expressing tumors and generally carry a favorable prognosis. Basal-like (BL) tumors lack both hormone receptor and HER2 expression. They are commonly seen in women who are BRCA1 carriers and generally positive for HER1 expression, basal cytokeratins and c-Kit. ${ }^{5,10,11}$ HER2 subtypes refer to predominantly hormone receptor-negative tumors with a specific gene expression pattern. Although not all tumors that are HER2/neu positive by clinical testing (immunohistochemistry and/or fluorescent in situ hybridization) strictly fall into this category ${ }^{4}$.

Several studies have demonstrated that BL tumors are not necessarily triple negative (TN). For instance, up to $15 \%-45 \%$ of $\mathrm{BL}$ tumors have been shown to express ER and $14 \%$ to express HER-2 ,indicating that not all of them regardless of classification method are $\mathrm{TN}^{3,5}$. Conversely, while $16 \%-44 \%$ of $\mathrm{TN}$ cases are negative for all basal markers (CK5/6, CK14, EGFR), $7.3 \%$ of non-TNBCs do express these $\mathrm{e}^{12-14}$. In later studies $71 \%$ of TNBCs were reported to be positive for at least one basal marker (i.e. CK5/6, CK17, CK14, EGFR) ${ }^{15}$.
The prevalence of TNBC in large unselected breast cancer patient cohorts is about $11 \%-20 \%$, whereas in selected cohorts of patients with advanced BC or patients of African-American ethnicity, TNBC may be diagnosed among as many as $23 \%-28 \%$ of all ${ }^{16,17}$. The close correlation with African- American ethnicity seems to be independent of an increased frequency of obesity in this patient population or age ${ }^{18}$. More than $90 \%$ of BLBCs/TNBCs exhibit an invasive ductal histology and high histological grade, present with high mitotic index and carry central necrotic zones and pushing borders as well as a conspicuous lymphocytic infiltrate. Consistent with its more aggressive biology, this BC subtype very often manifests itself as an interval cancer (i.e. diagnosed between screening mammograms) ${ }^{16}$. Furthermore, unifocality, mass lesion type, smooth mass margin, rim enhancement, persistent enhancement pattern and very high intratumoral signal intensity on T2-weighted magnetic resonance images are typical features associated with TNBC $^{19}$. Furthermore, TN breast tumors show enhanced 2-fluoro-2-deoxy-Dglucose (FDG) uptake allowing for detection of TNBC with a high sensitivity by using FDG-positron emission tomography (FDG-PET) ${ }^{20}$.

In numerous randomized trials, patients with $\mathrm{TN}$ or BL tumors treated by anthracyclines and taxanes experience a significantly decreased survival compared with patients with other tumor types. Importantly, the prognostic effect of TNBC is independent of poor grade, nodal status, tumor size and treatment ${ }^{21-23}$. The aggressiveness of TNBC is further indicated by the fact that the peak risk of recurrence occurs within the first 3 years after initial treatment of the disease with the majority of deaths occurring in the first 5 years and after diagnosis of metastatic disease, a significantly shorter survival was observed in both BL and TNBC. Conversely, the risk for late recurrences (i.e. beyond 5 years of diagnosis) is decreased by $50 \%$ compared with HR-positive disease ${ }^{24,25}$. However, differences between TNBC and non-TNBC regarding overall survival (OS) wear off at 10 years of follow-up. Cheang et al. ${ }^{20}$ recently hypothesized that the negative impact of TNBC on survival may be affected only by the subgroup of basal tumors within the TNBC group. Using the five-marker method described above, patients with BL TNBC had significantly decreased BC-specific OS compared with patients with the remaining non-basal TNBC; among patients treated by adjuvant anthracycline-based chemotherapy, the addition of basal markers allowed for identification of a subgroup with a significantly increased risk of relapse ${ }^{26}$. 
Although the association between TNBC and a less favorable prognosis has been clearly established, the effect on risk of local and distant recurrence remains less clear. There is a significant increased rate of visceral versus bone metastasis among patients with TNBC compared with non-TNBC ${ }^{27}$. In the largest report to date, data on 12858 patients indicate an increased risk for lung (OR 2.27) and brain (OR 5.32) metastasis as first site of recurrence and lower risk for bone recurrence (OR 0.23) in patients with TNBC ${ }^{16}$. Furthermore, Patients with TNBC compared with other subtypes reportedly experience an increased risk of central nervous system metastases (CM) of $6 \%-46 \%$ of those experiencing metastatic spread of disease $\mathrm{e}^{28}$.

By definition of their lack of receptors for ER, PR and HER2/ neu, patients with TNBC are not candidates for adjuvant hormonal therapy or trastuzumab. However, several studies showed that TNBC is associated with an increased response rate to (neoadjuvant) chemotherapy. The optimal chemotherapy regimen for these cancers remains to be determined ${ }^{29}$. A substantial minority of these cancers is highly sensitive to existing chemotherapies and their survival can be excellent if treated adequately as evidenced by the good long-term survival of patients with TNBC who achieve pathological complete remission (pCR) to preoperative chemotherapy. in contrast, patients who had residual invasive carcinoma after completion of neoadjuvant chemotherapy had a significantly shorter OS. This clearly demonstrates that the poor OS of TNBC is derived from the fraction of patients with chemoresistant disease unfortunately representing $>50 \%$ of TNBC. This observation underscores two important issues. First, novel diagnostic tools need to be developed allowing for the identification of those patients that are not sensitive to existing chemotherapies and are in need of alternative treatment options. Secondly and consequently, these patients require the development of novel therapeutic tools ${ }^{27}$.

Whereas patients with HER-2-overexpressing and/or topoisomerase-IIa-abnormal breast cancers have repeatedly been indicated to derive the most pronounced benefit from anthracycline-containing chemotherapy, results on the efficacy of anthracyclinebased regimens in patients with TNBC remain controversial $^{30}$. A recent meta-analysis from four studies investigating anthracycline-containing regimens versus cyclophosphamide-methotrexate-5-fluorouracil (CMF) showed that although benefit from anthracyclines was pronounced among patients with HER-2-positive disease, patients with TNBC still experienced a substantial 23\% reduction in the risk of disease relapse $(P=0.11)^{31}$. In the neoadjuvant setting, anthracycline-based regimens both with and without taxanes in this group are similarly efficacious $^{5}$. For instance, pCR rates after four to six courses of cyclophosphamide-epirubicin-5-fluorouracil (CEF) were $17 \%$ for patients with TNBC $^{32}$. Similarly, as enhanced response rates to anthracyclines may be achieved by increasing either dose intensity/density of the applied chemotherapy, an increase in pCR rate from $13 \%$ to $47 \%$ by intensifying conventional neoadjuvant FE100C chemotherapy to E70C700 $\mathrm{mg} / \mathrm{m} 2$ (d1+8) in combination with standard 5-FU (d1-5) has been reported ${ }^{33}$.

The association of TNBC with BRCA1 mutations and dysfunctional DNA repair may indicate an increased sensitivity toward DNA-damaging agents, i.e. platinum agents. A recent preclinical study demonstrated that overexpression of p63 (a p53-related transcription factor) and p73 (p53 associated as well) is common among TN cases and associated with sensitivity to cisplatin. However, despite an increasing amount of clinical data indicating platinum agents as carrying particular efficacy in TNBC, there are yet no randomized data identifying platinum-based chemotherapy as optimal regimen ${ }^{34}$.

Loss or inactivation of BRCA1 function is thought to be associated with particular sensitivity to DNAdamaging (e.g. alkylating) chemotherapy. Sensitivity of BRCA1-mutated cells to microtubule agents, like taxanes or vinca alkaloids, however, remains controversial. To date, there are limited data from randomized clinical trials investigating the impact of implementing taxanes into the adjuvant setting in patients with $\mathrm{TNBC}^{35}$. Hayes et al. illustrated that patients with either TN or HER-2positive $\mathrm{BC}$ derived the greatest benefit from the addition of four cycles of paclitaxel to four cycles of escalating doses of doxorubicin combined with a fixed dose of cyclophosphamide (AC) in 3170 node-positive patients ${ }^{36}$. Similarly, Citron et al. ${ }^{37}$ showed that the same dose-dense schedule particularly benefited patients with ER-negative tumors at an overall relative reduction in the hazard of recurrence of $32 \%$ and $19 \%$ for ER-negative and ERpositive BCs, respectively. However, this difference by ER status did not reach statistical significance ${ }^{37}$. The BCIRG 001 trial compared six cycles of TAC versus CAF in node-positive BC; in this study, patients with TNBC experienced a 3-year DFS rate of $73.5 \%$ after six cycles of TAC compared with $60 \%$ after six cycles of FAC $(\mathrm{HR}=0.50, \mathrm{P}=0.051)^{21}$. These data are corroborated by an excellent pCR to neoadjuvant six or eight cycles of TAC (supplemented by capecitabine/vinorelbine in those patients not responding after two cycles of TAC) among patients with TNBC in the GEPARTRIO trial ( $40.7 \%$ versus $31.6 \%$ ), particularly in patients $<40$ years of age $(60.0 \%)^{38}$.

At present, there are no randomized data justifying omission of anthracyclines or replacement thereof by alternative agents, such as platinum agents or taxanes, outside of clinical trials, particularly in the potentially curable adjuvant setting. Given that patients with TNBC resistant to chemotherapy are in need of effective novel therapeutic agents to prevent them from their particularly poor prognosis. Several biologically targeted agents are currently explored in this group, e.g. poly-ADP-ribose- 
polymerase-1 (PARP), epidermal growth factor receptor (EGFR), c-kit and Vascular Endothelial Growth Factor (VEGF) inhibitors either alone or in combination with chemotherapy and have shown promising results in numerous phase II trials ${ }^{39}$.

\section{REFERENCES}

1. Perou CM, Sorlie T, Eisen MB, van de Rijn M, Jeffrey SS, Rees CA, et al. Molecular portraits of human breast tumours. Nature 2000 Aug 17;406(6797):747-52.

2. Sørlie T. Molecular portraits of breast cancer: Tumour subtypes as distinct disease entities. Eur.J.Cancer 2004;40(18):2667-75.

3. Sorlie T, Perou CM, Tibshirani R, Aas T, Geisler S, Johnsen $\mathrm{H}$, et al. Gene expression patterns of breast carcinomas distinguish tumor subclasses with clinical implications. Proc.Natl.Acad.Sci.U.S.A. 2001 Sep 11;98(19):10869-74.

4. Brenton JD, Carey LA, Ahmed AA, Caldas C. Molecular classification and molecular forecasting of breast cancer: Ready for clinical application? J.Clin.Oncol. 2005 Oct 10;23(29):7350-60.

5. Rouzier R, Perou CM, Symmans WF, Ibrahim N, Cristofanilli M, Anderson K, et al. Breast cancer molecular subtypes respond differently to preoperative chemotherapy. Clin.Cancer Res. 2005 Aug 15;11(16):5678-85.

6. Sotiriou C, Neo SY, McShane LM, Korn EL, Long PM, Jazaeri A, et al. Breast cancer classification and prognosis based on gene expression profiles from a population-based study. Proc.Natl.Acad.Sci.U.S.A. 2003 Sep 2;100(18):10393-8.

7. Early Breast Cancer Trialists' Collaborative Group EBCTCG. Effects of chemotherapy and hormonal therapy for early breast cancer on recurrence and 15-year survival: An overview of the randomised trials. Lancet 2005 May 14-20;365(9472):1687-717.

8. Goldhirsch A, Wood WC, Gelber RD, Coates AS, Thürlimann B, Senn HJ. Progress and promise: Highlights of the international expert consensus on the primary therapy of early breast cancer 2007. Ann.Oncol. 2007;18(7):1133-44.

9. Sparano JA, Goldestin LJ, Childs BH, Shak S, Badve $\mathrm{S}$, Baehner FL, et al. Genotypic characterization of phenotypically defined triple-negative breast cancer. J.Clin.Oncol. 2009;27(Suppl):15s (Abstr. 500).

10. Dairkee SH, Puett L, Hackett AJ. Expression of basal and luminal epithelium-specific keratins in normal, benign and malignant breast tissue. J.Natl.Cancer Inst. 1988 Jul 6;80(9):691-5.

11. Honeth G, Bendahl PO, Ringnér M, Saal LH, Gruvberger Saal SK, Lövgren K, et al. The CD44+/CD24- phenotype is enriched in basal-like breast tumors. Breast Cancer Res. 2008;10(3):R53.

12. Rakha EA, El Sayed ME, Green AR, Lee AH, Robertson JF, Ellis IO. Prognostic markers in triple-negative breast cancer. Cancer 2007 Jan 1;109 (1): 25-32.

13. Tischkowitz M, Brunet JS, Begin LR, Huntsman DG, Cheang MC, Akslen LA, et al. Use of immunohistochemical markers can refine prognosis in triple negative breast cancer. BMC Cancer 2007;7:134.

14. Tan DSP, Marchió C, Jones RL, Savage K, Smith IE, Dowsett M, et al. Triple negative breast cancer: Molecular profiling and prognostic impact in adjuvant anthracyclinetreated patients. Breast Cancer Res.Treat. 2008;111(1): 27-44.

15. Rakha EA, Elsheikh SE, Aleskandarany MA, Habashi HO, Green AR, Powe DG, et al. Triple-negative breast cancer: Distinguishing between basal and nonbasal subtypes. Clin.Cancer Res. 2009;15(7):2302-10.

16. Lin NU, Vanderplas A, Hughes ME, Theriault RL, Edge SB, Wong Y, et al. Clinicopathological features and sites of recurrence according to breast cancer subtype in the National Comprehensive Cancer Network (NCCN). J.Clin.Oncol. 2009;27(Suppl):15s (Abstr. 543).

17. Dolle JM, Daling JR, White E, Brinton LA, Doody DR, Porter PL, et al. Risk factors for triple-negative breast cancer in women under the age of 45 years. Cancer Epidemiol.Biomarkers Prevent. 2009;18(4):1157-66.

18. Stead LA, Lash TL, Sobieraj JE, Chi DD, Westrup JL, Charlot $\mathrm{M}$, et al. Triple-negative breast cancers are increased in black women regardless of age or body mass index. Breast Cancer Res. 2009;11(2):R18.

19. Uematsu T, Kasami M, Yuen S. Triple-negative breast cancer: Correlation between MR imaging and pathologic findings. Radiology 2009;250(3):638-47.

20. Basu S, Chen W, Tchou J, Mavi A, Cermik T, Czerniecki $\mathrm{B}$, et al. Comparison of triple-negative and estrogen receptor-positive/progesterone receptor-positive/HER2negative breast carcinoma using quantitative fluorine-18 fluorodeoxyglucose/positron emission tomography imaging parameters: A potentially useful method for disease characterization. Cancer 2008;112(5):995-1000.

21. Hugh J, Hanson J, Cheang MCU, Nielsen TO, Perou CM, Dumontet $\mathrm{C}$, et al. Breast cancer subtypes and response to docetaxel in node-positive breast cancer: Use of an immunohistochemical definition in the BCIRG 001 trial. J.Clin.Oncol. 2009;27(8):1168-76.

22. Burnell MJ, O'Connor EM, Chapman JW, Levine MN, Pritchard KI, O'Brien PS, et al. Triple-negative receptor status and prognosis in the NCIC CTG MA.21 adjuvant breast cancer trial. J.Clin.Oncol. 2008 May 20;26(Suppl):Abstr. 550.

23. Jacquemier J, Penault Llorca F, Mnif H, Charafe Jauffret E, Marque S, Martin A, et al. Identification of a basallike subtype and comparative effect of epirubicin-based chemotherapy and sequential epirubicin followed by docetaxel chemotherapy in the PACS 01 breast cancer trial. 33 markers studied on tissue-microarrays (TMA). J.Clin.Oncol. 2006;24(Suppl 18s):5s (Abstr. 509).

24. Dent R, Trudeau M, Pritchard KI, Hanna WM, Kahn HK, Sawka CA, et al. Triple-negative breast cancer: Clinical features and patterns of recurrence. Clin.Cancer Res. 2007;13(15):4429-34.

25. Harris LN, Broadwater G, Lin NU, Miron A, Schnitt SJ, Cowan D, et al. Molecular subtypes of breast cancer in relation to paclitaxel response and outcomes in women 
with metastatic disease: Results from CALGB 9342. Breast Cancer Res. 2006;8(6):R66.

26. Cheang MCU, Voduc D, Bajdik C, Leung S, McKinney S, Chia SK, et al. Basal-like breast cancer defined by five biomarkers has superior prognostic value than triple-negative phenotype. Clin.Cancer Res. 2008;14(5): 1368-76.

27. Liedtke C, Mazouni C, Hess KR, André F, Tordai A, Mejia JA, et al. Response to neoadjuvant therapy and long-term survival in patients with triple-negative breast cancer. J.Clin.Oncol. 2008;26(8):1275-81.

28. Heitz F, Harter P, Traut A, Lueck HJ, Beutel B, du Bois A. Cerebral Metastases (CM) in Breast Cancer (BC) with focus on triple-negative tumors. J.Clin.Oncol. 2008;26(15S):Abstr. 1010.

29. Carey LA, Dees EC, Sawyer L, Gatti L, Moore DT, Collichio F, et al. The triple negative paradox: Primary tumor chemosensitivity of breast cancer subtypes. Clin. Cancer Res. 2007;13(8):2329-34.

30. Gennari A, Sormani MP, Pronzato P, Puntoni M, Colozza $M$, Pfeffer U, et al. HER2 status and efficacy of adjuvant anthracyclines in early breast cancer: A pooled analysis of randomized trials. J.Nat.Cancer Inst. 2008;100(1):14-20.

31. Di Leo A, Isola J, Piette F, Ejlertsen B, Pritchard KI, Bartlett JMS, et al. A meta-analysis of phase III trials evaluating the predictive value of HER2 and topoisomerase II alpha in early breast cancer patients treated with CMF or anthracycline-based adjuvant therapy. Cancer Res. 2009;69:Abstr. 705.

32. Bidard FC, Matthieu MC, Chollet P, Raoefils I, Abrial C, Dômont J, et al. p53 status and efficacy of primary anthracyclines/alkylating agent-based regimen according to breast cancer molecular classes. Ann.Oncol. 2008;19(7):1261-5.

33. Le Tourneau C, Dettwiler S, Laurence V, Alran S, Beuzeboc P, Pierga JY, et al. 47\% pathologic complete response rate to anthracyclinesbased associated with high cyclophosphamide doses neoadjuvant chemotherapy in basal-like and triple negative breast cancer patients. Breast Cancer Res.Treat. 2007;106:Abstr. 4010.

34. Leong CO, Vidnovic N, DeYoung MP, Sgroi D, Ellisen LW. The p63/p73 network mediates chemosensitivity to cisplatin in a biologically defined subset of primary breast cancers. J.Clin.Invest. 2007 May;117(5): 1370-80.

35. Kennedy RD, Quinn JE, Mullan PB, Johnston PG, Harkin DP. The role of BRCA1 in the cellular response to chemotherapy. J.Nat.Cancer Inst. 2004;96(22): 1659-68.

36. Hayes DF, Thor AD, Dressler LG, Weaver D, Edgerton S, Cowan D, et al. HER2 and response to paclitaxel in node-positive breast cancer. N.Engl.J.Med. 2007;357(15):1496-506.

37. Citron ML, Berry DA, Cirrincione C, Hudis C, Winer EP, Gradishar WJ, et al. Randomized trial of dose-dense versus conventionally scheduled and sequential versus concurrent combination chemotherapy as postoperative adjuvant treatment of node-positive primary breast cancer: First report of Intergroup Trial C9741/Cancer and Leukemia Group B Trial 9741. J.Clin.Oncol. 2003 Apr 15;21(8):1431-9.

38. Huober J, von Minckwitz G, Denkert C, Kleine Tebbe A, Weiss E, Zahm D, et al. Neoadjuvant chemotherapy in operable breast cancer with docetaxel, doxorubicin and cyclophosphamide (TAC) or TAC followed by vinorelbine and capecitabine (NX): Final results and analysis of markers predicting response to treatment. J.Clin.Oncol. 2009;27(Suppl):15s (Abstr. 524).

39. Gluz O, Liedtke C, Gottschalk N, Pusztai L, Nitz U, Harbeck N. Triple-negative breast cancer - Current status and future directions. Ann.Oncol. 2009;20(12): 1913-27. 